Energy Research Journal 1 (2): 135-140, 2010

ISSN 1949-0151

(C) 2010 Science Publications

\title{
The Influence of Foam Density on Specific Energy Absorption of Rectangular Steel Tubes
}

\author{
Nirut Onsalung, Chawalit Thinvongpituk and Kulachate Painthong \\ Department of Mechanical Engineering, Faculty of Engineering, \\ Ubon Ratchathani University, Ubonratchathani, Thailand 34190
}

\begin{abstract}
Problem statement: In general, the automotive structure is targeted to absorb high impact energy with least mass as much as possible. This is in order to limit the fuel consumption. Therefore, various techniques to increase the energy absorption with less mass increment have been studied for years. One of those techniques is by filling foam in the tube. This study is also aimed to investigate more detail of the behavior of foam-filled structure under impact. Approach: The study was carried out experimentally by using steel tubes of 2 dimensions i.e., $1 \times 2$ and $2 \times 2$ inch $^{2}$. The thickness of each tube was varied from 1.2, 1.5 and $1.8 \mathrm{~mm}$. Each tube was filled with polyurethane foam. The density of foam was varied from 100, 200 and $300 \mathrm{~kg} \mathrm{~m}^{-3}$. The foam-filled tubes were crushed axially using a $1,000 \mathrm{kN}$ universal testing machine. The crush speed was $50 \mathrm{~mm} \mathrm{~min}^{-1}$. The load - displacement were recorded and the energy absorption of each specimen was calculated and compared. In this study the specific energy absorption was used as a key indicator, rather than energy absorption, in order to take the mass increment into account. Results: The experimental observation revealed that the structures failed in square mode with number of fold increases as the density of foam increased. It also found that the foam filled tube with density of $300 \mathrm{~kg} \mathrm{~m}^{-3}$ absorb energy more than that of the tube with foam of 200 and $100 \mathrm{~kg} \mathrm{~m}^{-3}$ density and empty tube respectively. However, when taking mass into account, the tube with $200 \mathrm{~kg} \mathrm{~m}^{-3}$ foam-filled may be the most efficient since it provided maximum specific energy absorption value. Conclusion: The result indicated that the density of foam increases the number of folds in collapsed tubes. The result also revealed that tube with higher density foam can absorb more energy absorption. In addition, it was found that the density of $200 \mathrm{~kg} \mathrm{~m}^{-3}$ is the optimum value to fill in tube since it offers maximum specific energy absorption.
\end{abstract}

Key words: Foam-filled, energy absorption, steel tube, impact energy, crashworthiness

\section{INTRODUCTION}

Automotive structure is one of most important component in vehicles since its function is to protect the passenger room. In general, motor vehicle structures are using steel tube or aluminum tube with different geometries for main structures. There are many geometrical shapes used in vehicle structures such as rectangular shape, circular shape, U-shape and L-shape. In this respect, attention has been directed towards the crash energy management and the structural integrity of the vehicle body parts. The parts are requiring to high crashworthiness for protecting the passengers. Many studies indicated that crushing behavior should be concerned throughout their specific energy absorption under impact load. That is to say, the structure must be properly collapse and should be much considered the weight of structure. In another word, the structure should be high energy absorption when compare to its mass (Zhang et al., 2007; Aktay et al., 2006). The specific energy absorption can be defined that the energy absorption capacity per unit mass of structure and is given by:

$$
E_{s}=\frac{E_{a}}{\text { mass }}
$$

Where:

$\mathrm{E}_{\mathrm{s}} \quad=$ Specific energy absorption mass $=$ Mass of structure:

$$
\mathrm{E}_{\mathrm{a}}=\int_{0}^{\mathrm{S}} \mathrm{PdS} \approx \mathrm{P}_{\text {mean }} \times \mathrm{S}
$$

Where:

Corresponding Author: Nirut Onsalung, Department of Mechanical Engineering, Faculty of Engineering,

Ubon Ratchathani University, Ubonratchathani, Thailand 34190 Tel: +6645-353309 Fax: +6645-353308 
Energy Rec. J. 1 (2): 135-140, 2010

$\mathrm{E}_{\mathrm{a}} \quad=$ Energy absorption

$\mathrm{P}_{\text {mean }}=$ Mean compressive force and

$\mathrm{S} \quad=$ Stroke displacement

To meet that requirement, new material for structural applications such as fiber-reinforced composite was introduced and investigated (Savage et al., 2004). In another approach, the use of foam-filled materials in automotive structures may result in many potential economic and functional benefits due to their improved properties. Therefore, investigators have conducted some studies cornering on aluminum foam-filled in the structures (Hanssen et al., 2002; Langseth and Hopperstad, 1996; Seitzberger, 2000). Recent study (Mamalis, 2009) revealed that the use of aluminium foam and polyurethane foam may enhance the structural crashworthy of rectangular tube. In addition the use of foam-filled in other geometry sections has also investigated such as S-shape (Kim et al., 2002) and hatsections (Song et al., 2005). The study is aimed to investigate the behavior of polyurethane foam-filled rectangular tube subjected to quasi-static axial crush. The influence of foam density, tube thickness and cross-section is focused.

\section{MATERIALS AND MATHODS}

Materials: The specimens that using in this study are made from carbon steel AISI 1020, whose crosssectional shape is $2 \times 2$ inch $^{2}$ square tube and $1 \times 2$ inch $^{2}$ rectangular tube with $150 \mathrm{~mm}$ height. The density of steel is about $7,700 \mathrm{~kg} \mathrm{~m}^{-3}$, Young's modulus is about $200 \mathrm{GPa}$ and Poisson's ratio is 0.3 , all measure at $25^{\circ} \mathrm{C}$. The thickness of tube is uniform and ranged form 1.2, 1.5 and $1.8 \mathrm{~mm}$. The tubes are filled with polyurethane foam of different densities i.e. 100,200 and $300 \mathrm{~kg} \mathrm{~m}^{-3}$. The specimens are made in triplicate in order to repeat the test. Therefore, there are totally 36 pieces of specimen for each section, including empty tubes. The property of Polyurethane foam (PU foam) is tested based on some standard tests listed in Table 1. The important properties of foam such as density $30 \mathrm{~kg} \mathrm{~m}^{-3}$ for free rise and about $1.5-2.0 \mathrm{~kg} \mathrm{~cm}^{-2}$ of compressive strength. PU foam is formed when two chemicals a diisocyanate and a polyol are mixed together. It can be attachable to almost all types of paper, steel, concrete, tiles, plywood and aluminum, which are outstanding characteristics that light weight and strength. The foamfilled specimens are shown in Fig. 1.

Experimental procedure: The ready foam-filled specimens were, then, tested by quasi-static axially crush. The experiment was performed using the $1000 \mathrm{kN}$ universal testing machine as shown in Fig. 2.
Table 1: Standards for polyurethane test in this study

\begin{tabular}{ll}
\hline Property & Standard test \\
\hline Density & ISO845 \\
Water absorption & ASTM D-2842 \\
Compressive strength & ISO 844 \\
Flammability & Din 4102 \\
\hline
\end{tabular}

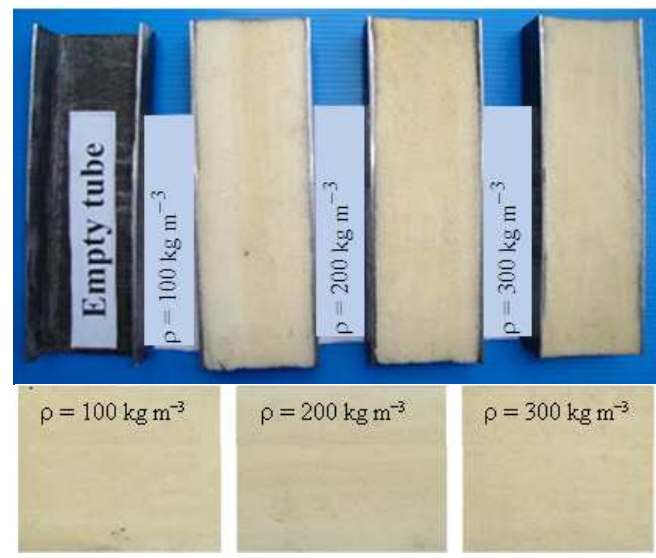

Fig. 1: Illustrate the cross-section of empty and foamfilled tube tested in this study

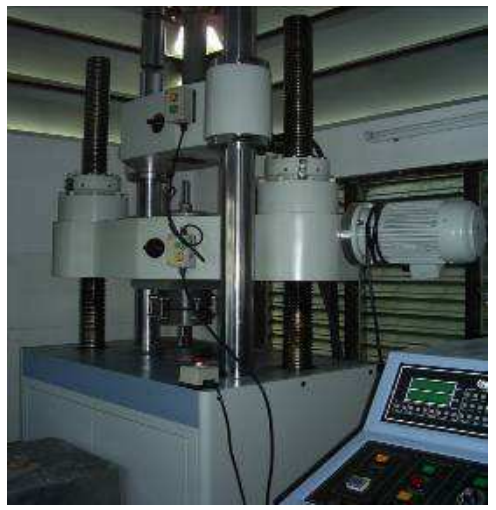

Fig. 2: The universal testing machine

The specimen was unloaded and the experiment stopped when the tube collapsed until $60 \%$ of the original height. Reaction force and displacement were recorded and used to calculate for $\mathrm{E}_{\mathrm{s}}$ and $\mathrm{E}_{\mathrm{a}}$.

\section{RESULTS}

Mode of collapse: When rectangular tube is axially crush, it normally deforms in a so-called square mode. This mode is also observed in the specimens tested in the present. Figure 3 shows some example of the progressive collapse of foam-filled tubes by forming square folding lobe from one end. Then, as the previous lobe is complete, the adjacent folding lobe is formed on top and stack on each other. This process continues in series until the test is terminated. 
The final deformation mode of foam-filled tubes is summarized in Table 2. The summary is characterized regarding to geometrics and foam-fill density. It is observed from Table 2 that the empty tubes generally fail into square mode with 2 folds. Considering the tubes that are filled with $100 \mathrm{~kg} \mathrm{~m}^{-3}$ density foam, they mostly fail into 3 folds. In case of the tubes of $200 \mathrm{~kg} \mathrm{~m}^{-3}$ density foam-filled, majority of them (about $67 \%$ ) fail into 3 folds and the rest (about 33\%) fail into 4 folds. In case of $300 \mathrm{~kg} \mathrm{~m}^{-3}$ foam-filled tube, majority of them (67\%) fail into 4 folds, some of them (16.5\%) fail into 3 folds and some of them fail into 5 folds.
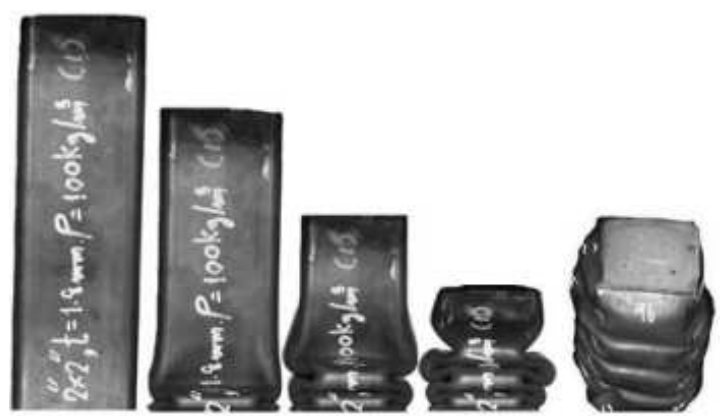

(a)

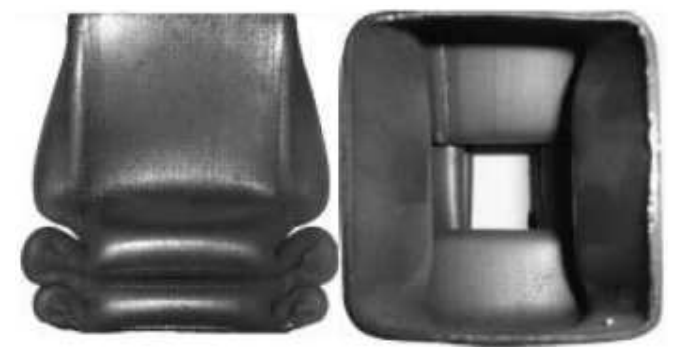

(b)

Fig. 3: The deformation of specimens. (a) histories collapse pattern; (b) square mode pattern

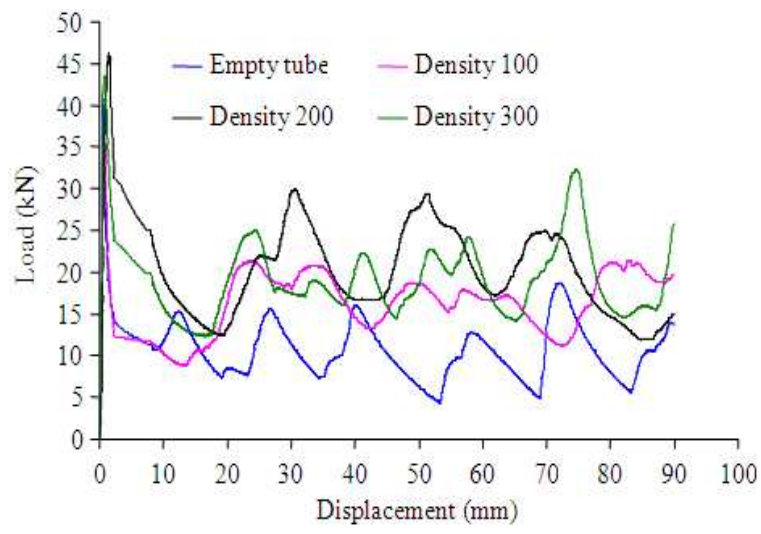

(a)
Load-displacement history: As the specimens were being crushing, the reaction force and corresponding displacement were recorded. These data were, then, plotted and the curve is call load-displacement curve.

The load-displacement curves of empty and foamfilled tubes are shown in Fig. 4a-4f. It is observe that the curves are fluctuating in wavy shape. The first peak of every curve is highest and is maximum load. The following peaks in each graph normally lie in the same magnitude.

Number of peaks is corresponding to number of lobes in deformed specimens. It is also observed that the load-displacement curve of foam-filled tubes with higher density trend to lie above the tubes filled with lower density foam and empty tube.

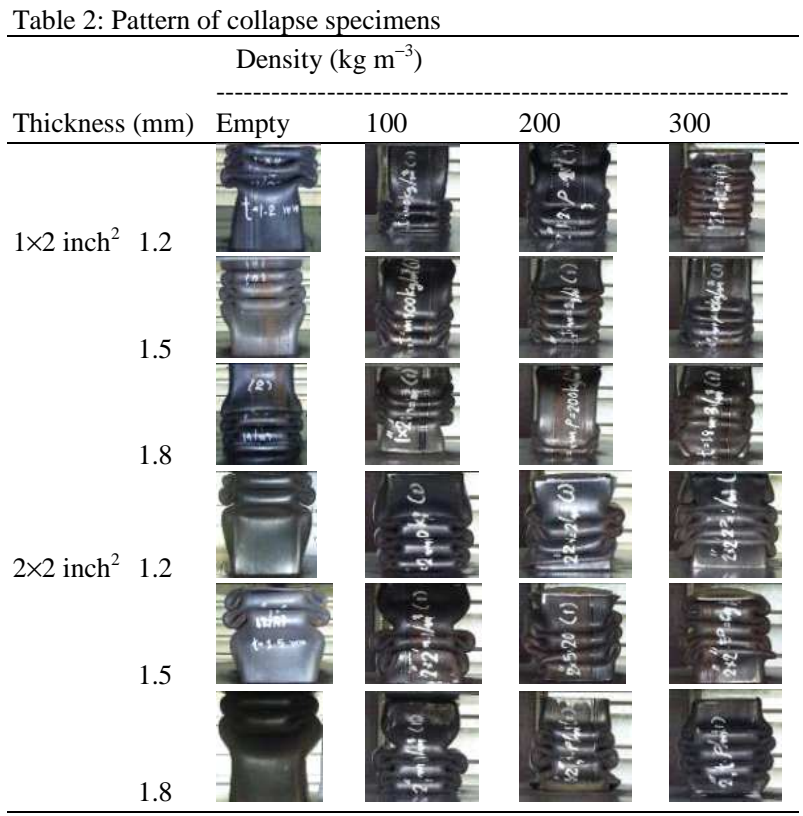

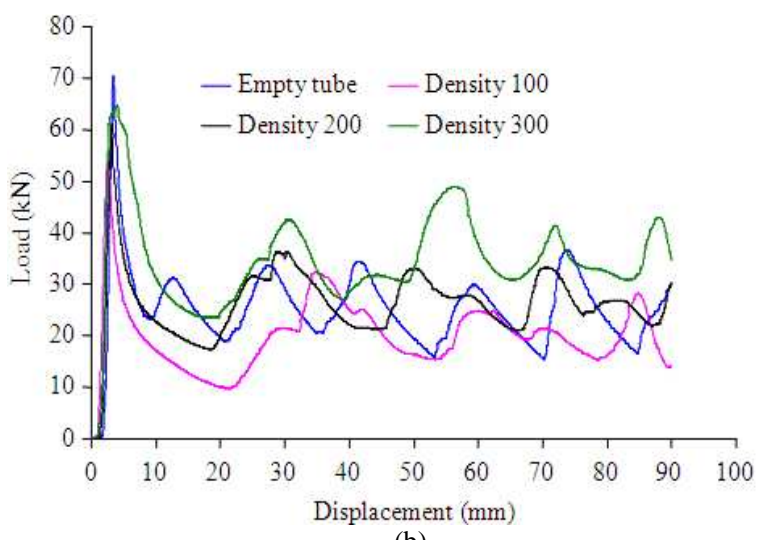

(b) 
Energy Rec. J. 1 (2): 135-140, 2010

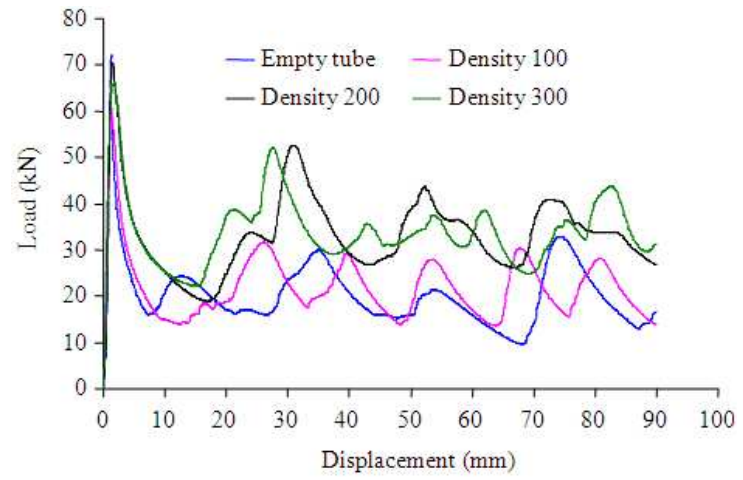

(c)

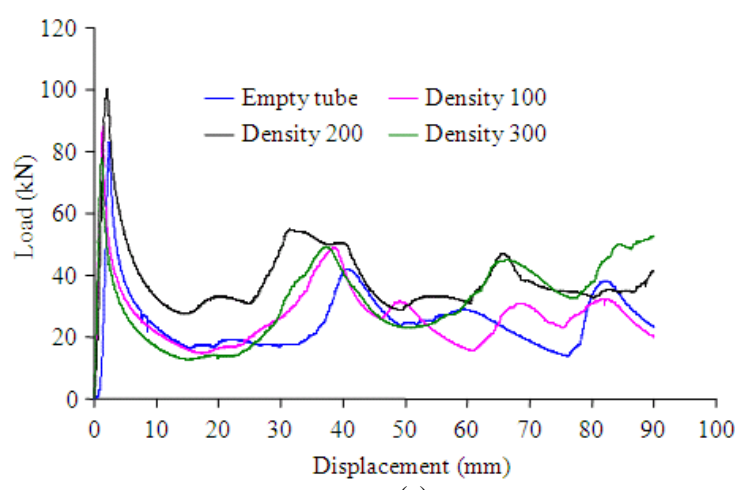

(e)

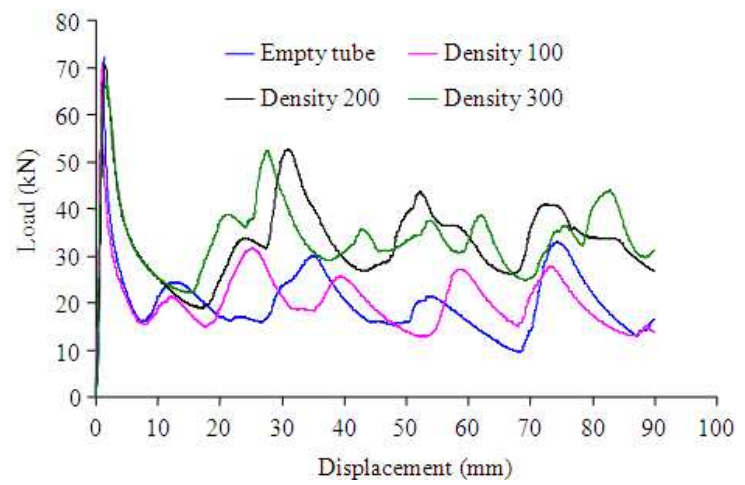

(d)

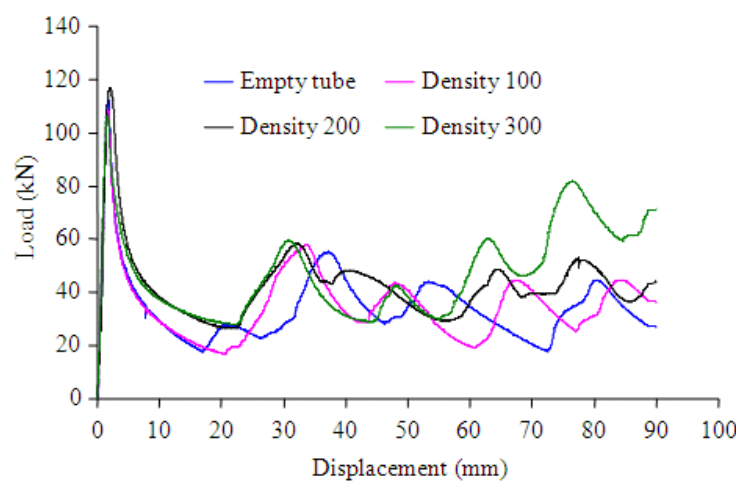

(f)

Fig. 4: Load-displacement curve of crushed tubes. (a) $1 \times 2$ inch $^{2}$ tube of $1.2 \mathrm{~mm}$ thickness; (b) $1 \times 2$ inch $^{2}$ tube of $1.5 \mathrm{~mm}$ thickness; (c) $1 \times 2 \mathrm{inch}^{2}$ tube of $1.8 \mathrm{~mm}$ thickness; (d) $2 \times 2 \mathrm{inch}^{2}$ tube of $1.2 \mathrm{~mm}$ thickness; (e) $2 \times 2$ inch $^{2}$ tube of $1.5 \mathrm{~mm}$ thickness; (f) $2 \times 2$ inch $^{2}$ tube of $1.8 \mathrm{~mm}$ thickness

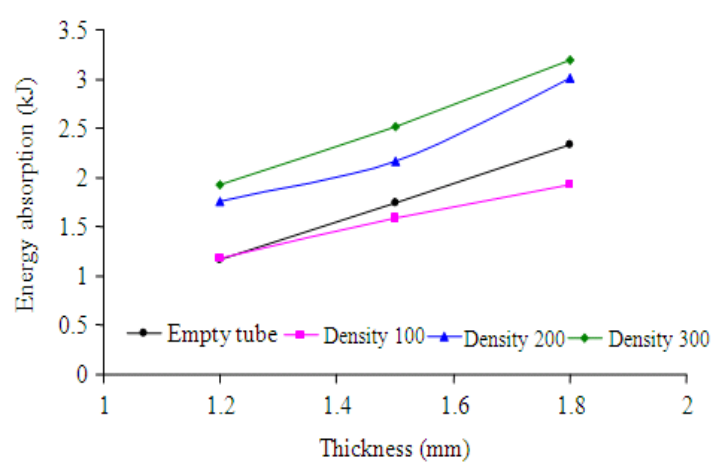

Fig. 5: The energy absorption of empty and foamfilled $1 \times 2$ inch $^{2}$ tube with different condition

Energy absorption capacity: The energy absorption $\left(E_{a}\right)$ of each tube is defined as the energy required to cause the collapse mode observed. The energy is converted firstly into elastic strain energy in the deform tube and the remainder is dissipated in plastic deformation during collapse.
Table 3: Illustrates specific energy absorption $\left(E_{S}: \mathrm{kJ} \mathrm{kg}^{-1}\right)$ of tested

\begin{tabular}{cccccc}
\multicolumn{5}{c}{ tubes } & \multicolumn{4}{c}{} \\
\hline \multicolumn{5}{c}{ Foam density $\left(\mathrm{kg} \mathrm{m}^{-3}\right)$} \\
\multicolumn{1}{c}{ Thickness $(\mathrm{mm})$} & Empty & 100 & \multicolumn{1}{c}{ 200 } & \multicolumn{1}{c}{300} \\
\hline $1 \times 2$ inch $^{2}$ & 1.2 & 6.88 & 6.93 & 9.51 & 9.15 \\
& 1.5 & 8.94 & 7.91 & 9.84 & 11.18 \\
$2 \times 2$ inch $^{2}$ & 1.8 & 11.65 & 9.17 & 12.54 & 12.04 \\
& 1.2 & 7.76 & 6.46 & 7.95 & 7.51 \\
& 1.5 & 7.82 & 6.98 & 8.89 & 7.68 \\
& 1.8 & 9.04 & 8.31 & 9.90 & 10.32 \\
\hline
\end{tabular}

The energy absorption $\left(\mathrm{E}_{\mathrm{a}}\right)$ and Specific Energy absorption $\left(E_{\mathrm{s}}\right)$ of specimens were calculated using Eq. 1 and 2, with the data from load-displacement curves. The results are shown in Table 3 and plotted in Fig. 5-8 in order to compared.

It is observed from Fig. 5 and 7 that the energy absorption of tubes are increasing as the thickness increased. In addition the tubes with higher density foam filled trend to absorb more energy. Considering the specific energy absorption $\left(\mathrm{E}_{\mathrm{s}}\right)$ in Fig. 6 and 8, it was observed that the tube with $100 \mathrm{~kg} \mathrm{~m}^{-3}$ foamfilled provide lowest value of $E_{s}$ while the tube with 200 and $300 \mathrm{~kg} \mathrm{~m}^{-3}$ foam-filled give high value of $\mathrm{E}_{\mathrm{s}}$. 


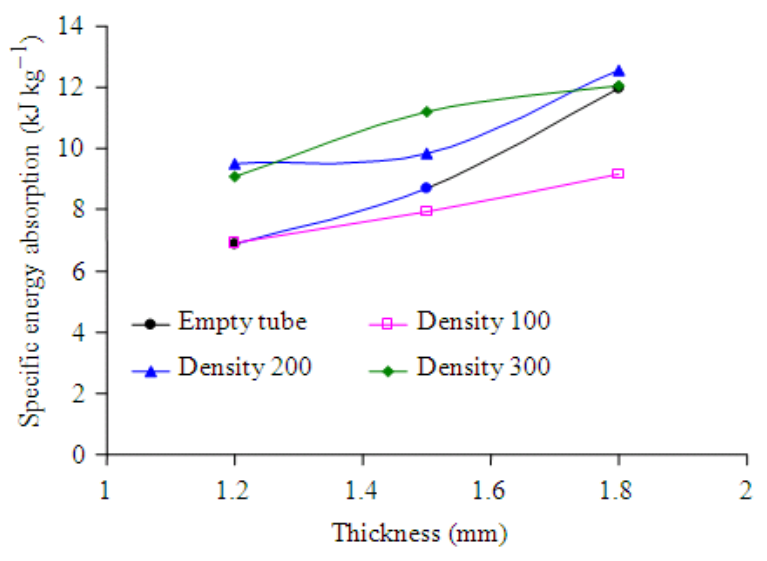

Fig. 6: The specific energy absorption of empty and foam-filled $1 \times 2$ inch $^{2}$ tubes

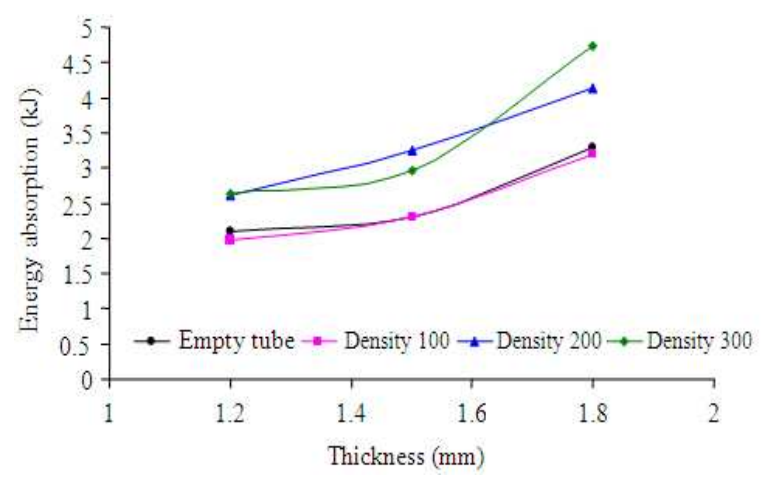

Fig. 7: The energy absorption of empty and foam-filled $2 \times 2$ inch $^{2}$ tube with different condition

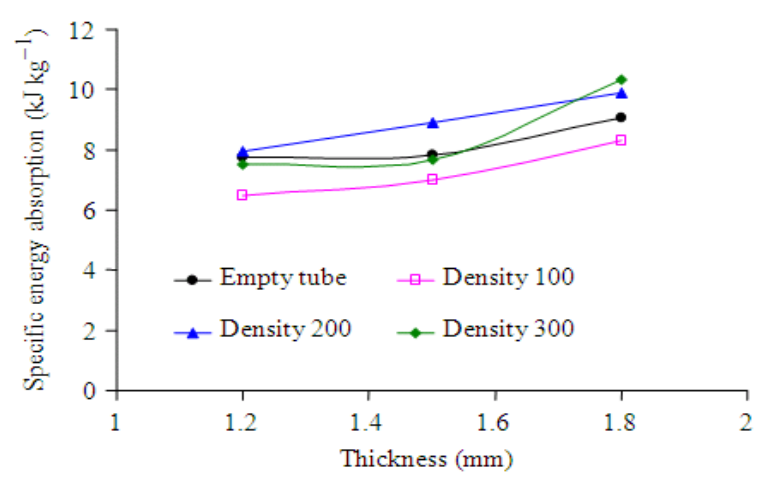

Fig. 8: The specific energy absorption of empty and foam-filled $2 \times 2 \mathrm{inch}^{2}$ tubes

\section{DISCUSSION}

When the empty tubes and foam-fill tubes were crush they failed in square mode with a number of folds. The result suggested that the number of folds tend to increase as the density of foam is increased. This may be because the impact energy distributes to the whole structure with the assistance of foam. In addition the foam in structure also help to absorb energy, therefore higher energy absorption was observed in high density foam-filled tube.

In the view of specific energy absorption foam fill with small density may cause lower specific energy absorption because it increase the mass more than increase the energy absorption capacity. The lowest value of $E_{s}$ for $100 \mathrm{~kg} \mathrm{~m}^{-3}$ foam filled tube is an evidence of this. However, the tube with higher density foam filled, i.e., $200-300 \mathrm{~kg} \mathrm{~m}^{-3}$, still provide higher value of $E_{s}$.

It is also found that the $200 \mathrm{~kg} \mathrm{~m}^{-3}$ foam-filled tubes offer higher specific energy absorption than the $300 \mathrm{~kg} \mathrm{~m}^{-3}$ foam-filled tube. This can be explained that the weigh of $300 \mathrm{~kg} \mathrm{~m}^{-3}$ foam-filled tube is more than that of the $200 \mathrm{~kg} \mathrm{~m}^{-3}$ foam-filled tubes.

\section{CONCLUSION}

The present study reveals the failure characteristic of foam-filled tubes. It was found that the number of folds in deformed tube is increasing as the density of foam increases. In addition, the result suggests that the tube tends to absorb more energy as the density of foam increases. However, considering the structural weight, the result indicates that the $200 \mathrm{~kg} \mathrm{~m}^{-3}$ foam-filled tube offer highest specific energy absorption. This implies the mentioned tube may be the most crashworthy element.

\section{ACKNOWLEDGEMENT}

This research was granted by the Office of the Higher Education Commission, Thailand under the program Strategic Scholarships for Frontier Research Network for the Ph.D. program, together with Ubon Ratchathani University, Thailand.

\section{REFFERENCES}

Aktay, L., A.K. Toksoy and M. Guden, 2006. Quasistatic axial crushing of extruded polystyrene foamfilled thin-walled aluminum tubes: Experimental and numerical analysis. Mater. Des., 27: 556-565. DOI: 10.1016/j.matdes.2004. 12.019

Hanssen, A.G., O.S. Hopperstad and M. Langseth, 2002. Validation of constitutive models applicable to aluminum foams. Int. J. Mech. Sci., 44: 359-406. DOI: 10.1016/S0020-7403(01)00091-1 
Kim, H.S., W. Chen and T. Wierzbicki, 2002. Weight and crash optimization of foam-filled three dimensional "S" frame. Int. J. Comput. Mech., 28: 417-424. DOI: 10.1007/s00466-002-0306-2

Langseth, M. and O.S. Hopperstad, 1996. Static and dynamic axial crushing of square thin-walled aluminum extrusions. Int. J. Impact Eng., 18: 949-968. DOI: 10.1016/S0734-743X (96)00025-5

Mamalis, A.G., 2009. On the crashworthiness of composite rectangular thin-walled tubes internally reinforced with aluminum or polymeric foams: Experimental and numerical simulation. Int. J. Compos. Struct., 89: 416-423. DOI: 10.1016/j. compstruct.2008.09.008

Savage, G., I. Bomphray and M. Oxley, 2004. Exploiting the fracture properties of carbon fiber composites to design lightweight energy absorbing structures. Int. J. Eng. Fail. Anal., 11: 677-694. DOI: 10.1016/j.engfailanal.2004.01.001

Seitzberger, M., 2000. Experimental studies on the quasi-static axial crushing of steel columns filled with aluminum foam. Int. J. Solids Struct., 37: 4125-4147. DOI: $10.1016 /$ S0020-7683(99) 00136-5
Song, H.W., Z.J. Fan, G. Yu, Q.C. Wang and A. Tobota, 2005. Partition energy absorption of axially crushed aluminum foam-filled hat sections. Int. J. Solids Struct., 42: 2575-2006. DOI: 10.1016/j.ijsolstr.2004.09.050

Zhang, X., G. Cheng, Z. You and H. Zhang, 2007. Energy absorption of axially compressed thinwalled square tubes with patterns. Thin-Walled Struct., $45: \quad 737-746 . \quad$ DOI: 10.1016/j.tws.2007.06.004 